\title{
Apontamentos sobre a inserção das pessoas com transtorno mental no trabalho formal
}

\author{
Notes on the inclusion of people with mental disorder \\ in formal labor
}

Tathiana Meyre da Silva Gomes*

\begin{abstract}
Resumo - Este artigo problematiza a importância do trabalho formal e com direitos para as pessoas com transtorno mental, a partir dos resultados de pesquisa da Tese de Doutorado. A pesquisa foi realizada com 17 participantes vinculados a dois projetos de inserção de pessoas com transtorno mental no município do Rio de Janeiro e consistiu na realização de entrevista semiestruturada e observação assistemática. Dentre os resultados, percebeu-se que, apesar dos efeitos deletérios provocados pela forma social que o trabalho assume no sistema capitalista e, em função da associação cultural e simbólica vigente no senso comum entre trabalho e normalidade, a inserção formal no trabalho figura no imaginário das pessoas com transtorno mental como atividade produtiva ideal, com capacidade de forjar pertencimento e reconhecimento social, independente do retorno monetário.

Palavras-chave: trabalho; capitalismo; reforma psiquiátrica; saúde mental.

Abstract - This article discusses the importance of formal labor and its accompanying rights for people with mental disorder, following from the results of a doctoral thesis research. This survey consists of semi-structured interviews and systematic observation. It was conducted with 17 participants linked to two projects promoting inclusion of people with mental disorders in the city of Rio de Janeiro. Among the results, it was noted that despite the deleterious effects caused by the social form work assumes in the capitalist system, and because of the prevailing cultural and symbolic association in common sense between work and normality, formal inclusion in labor appears in the imagination of people with mental disorders as the ideal productive activity, being able to forge social belonging and recognition, regardless of monetary compensation.
\end{abstract}

Keywords: work; capitalism; psychiatric reform; mental health.

\footnotetext{
*Assistente social. Doutora em Serviço Social (PUC-Rio) e Professora da Escola de Serviço Social da Universidade Federal Fluminense. Correspondência: Rua Araguaia, 1425/ apt 303 - Freguesia, Rio de Janeiro. CEP: 22745271. Email: <tathianagomes@id.uff.br>.
} 


\section{Introdução}

A temática do trabalho mobiliza estudos e pesquisas em diversas áreas do conhecimento. Por meio do trabalho o homem se originou enquanto ser qualitativamente distinto dos outros seres, elevando-se à condição de único capaz de forjar a realidade, ao invés de estar unilateralmente subsumido a ela (KOSIK, 2011).

No entanto, na formação social capitalista, o trabalho assume, além da condição acima indicada, um caráter distinto. Se, do ponto de vista ontológico, considera-se o trabalho como atividade fundante do ser social, na sociedade capitalista ele assume centralidade, dada a sua forma social específica e a sua relevância para a reprodução do valor (LUKÁCS, 1979; DUAYER, 2012; POSTONE, 2014).

Dada essa centralidade, o processo histórico que culmina com a transformação do trabalho de expiação à virtude - necessidade posta para a consolidação do capitalismo - contribui para forjar, no polo oposto ao imaginário social de valorização do trabalho, a identificação daqueles sem ocupação com a figura do vagabundo. É, pois, uma relação que opõe o trabalho como virtude ao não trabalho como indolência'.

A servidão do trabalho foi assumida como o único caminho possível para a salvação dos homens, que não deveriam demonstrar resistência ao seu destino, sob o risco de incorrerem em novo pecado: a preguiça. A associação entre preguiça e pecado (a preguiça é elencada como sexto pecado capital) nutre, no imaginário social, representações negativas acerca do não trabalho, da ociosidade. Aquele que recusa, resiste ou não se insere no trabalho por qualquer outra razão que não as sancionadas socialmente é classificado como vagabundo, indolente e digno de condenação (concreta e simbólica).

Uma vez estabelecida a associação entre preguiça/ociosidade e pecado (o inconveniente e o proscrito) e instituído o trabalho como virtude, portanto, o seu agente como ser virtuoso e desejável, coloca-se a necessidade de se instaurar, no polo oposto, lugares sociais para aqueles que, por razões distintas, não se enquadravam na lógica societal do capital. No caso das pessoas com transtorno mental, quanto mais os novos ritmos de trabalho e de vida foram se instituindo com a consolidação do capitalismo, mais esse processo reforçava a marca da inutilidade que havia recaído sobre eles no referido sistema social. Associada à proscrição do ócio, foi preciso dar destino a esses sujeitos: o manicômio e a psiquiatria clássica acabam por operar a interdição social da loucura.

A relação entre trabalho e loucura não é homogênea e assume distintas formas e sentidos nos diferentes momentos históricos (prática de

\footnotetext{
${ }^{1}$ Analisando o processo que denominou como a invenção do trabalhismo no Brasil, Gomes (2010) observa que o esforço para a criação de uma valorização, de uma ética do trabalho, desenvolveu também, como forma de resistência, uma ética do não trabalho, da malandragem.
} 


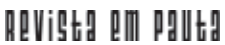

\} APONTAMENTOS SOBRE A INSERÇÃO DAS PESSOAS COM TRANSTORNO - GOMES, T. M. S. \}

DOI $10.12957 /$ REP.2017.30383

normatização, castigo, disciplinamento no interior das grandes instituições, terapia e cidadania). Desse modo, a associação entre trabalho e psiquiatria não é nova e remonta ao surgimento do próprio manicômio, no qual a atividade laborativa era utilizada como meio de troca, castigo, premiação por bom comportamento ou como mecanismo de redução de custos da instituição. Evidencia-se, assim, um dos sentidos conferido ao trabalho no interior do ambiente institucional, qual seja, o da realização de tarefas determinadas por terceiros e com pouco ou nenhum reconhecimento (NICÁCIO, MANGIA, GHIRARDI, 2005; MÂNGIA, 1997).

A reforma levada a cabo por Philippe Pinel (1745-1826) no século XVIII forjou uma nova tradição, no sentido de que "suas propostas aderiram ao ideário revolucionário sendo representadas em termos de: liberdade no manicômio, igualdade entre os sãos e doentes e fraternidade, como filantropia e esclarecimento" (FACCHINETTI, 2008, p. 3).

Na perspectiva pineliana, o tratamento moral tinha início com a prática do isolamento, seguida da aplicação do regime de disciplina rigoroso da instituição. A utilização do trabalho (obrigatório, por vezes) era concebida como um elemento terapêutico fundamental na organização da consciência, na instituição da disciplina e na posterior adaptação do sujeito à realidade.

A partir da segunda metade do século XX multiplicaram-se experiências em âmbito internacional, especialmente nos países de economia capitalista avançada, voltadas à transformação da assistência às pessoas com transtorno mental. Essas experiências culminaram na realização, em vários países, de distintas reformas psiquiátricas, a saber: Comunidade Terapêutica e Psiquiatria Institucional nos anos de 1940; Psiquiatria Preventiva, Psiquiatria de Setor e Antipsiquiatria, nos anos de 1960; e Psiquiatria Democrática Italiana na década de 1970.

Ao discorrer sobre as razões para a emergência desses movimentos de contestação em países do Ocidente, Basaglia (2005) destaca que, no capitalismo avançado, as práticas repressivas baseadas nos critérios originais de anormalidade não poderiam mais ser aceitas, entre outras coisas, em função da baixa tolerância, naquele período, a práticas totalitárias de enclausuramento e degradação humana. Esse contexto instituiu uma atmosfera de resistência às situações de violência, como aquelas vivenciadas em internações do tipo carcerárias.

Algumas dessas experiências passam a reivindicar a extensão dos direitos civis e sociais para aqueles que viviam institucionalizados nos manicômios, questionando a possiblidade de inserção dessas pessoas no trabalho. Esse movimento foi mais intenso nos países em que a reforma psiquiátrica teve como base a perspectiva da desinstitucionalização, como ocorreu na Itália e no Brasil².

\footnotetext{
${ }^{2}$ A reforma psiquiátrica tem início no Brasil entre os anos de 1970 e 1980, no contexto de redemocratização do cenário sociopolítico, sendo profundamente influenciada pela reforma psiquiátrica italiana. Nos anos de 1990, as diretrizes da reforma psiquiátrica são incorporadas, constituindo-se como política oficial de governo, expressa na atual Política Nacional de Saúde Mental, Álcool e outras Drogas.
} 


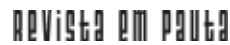

\} APONTAMENTOS SOBRE A INSERÇÃO DAS PESSOAS COM TRANSTORNO - GOMES, T. M. S. \} DOI 10.12957/REP.2017.30383

O presente artigo busca problematizar a relevância que o trabalho formal (com vínculo celetista) assume para as pessoas com transtorno mental, considerando o processo de reforma psiquiátrica em curso no país centrado nas propostas de desinstitucionalização e cidadania. É produto da pesquisa realizada para a Tese de Doutorado em que se buscou conhecer o processo de implementação da Lei n. 8.213/91 no que tange à inserção das pessoas com transtorno mental no trabalho formal, tal qual consta no aditivo do Ministério Público do Trabalho do Rio de Janeiro de abril de 2012 (GOMES, 2014).

Para a referida pesquisa foram entrevistados 17 participantes, dos quais 12 eram usuários dos serviços de saúde mental inseridos em programas voltados para a inclusão no trabalho formal, três eram profissionais e dois eram gestores. A tese teve por objetivo identificar os sentidos e a importância da inserção no trabalho formal para as pessoas com transtorno mental em tratamento de saúde mental no município do Rio de Janeiro. Buscou-se identificar os mecanismos jurídico-legais que vêm possibilitando que essa inserção ocorra e o significado que o trabalho possui para esses sujeitos, assim como a repercussão que a inserção no trabalho formal teve em suas vidas.

Em relação à coleta de dados, entrevistou-se usuários que participavam dessas ações de inserção no trabalho formal com o intuito de conhecer os sentidos que a realização das atividades de trabalho possui em suas vidas. Ademais, pretendeu-se identificar as possíveis repercussões de sua inserção no trabalho no que tange às necessidades objetivas (no nível de reprodução material) e às suas expectativas subjetivas (se a inserção no trabalho formal alterou a representação que o usuário possuía sobre si, por exemplo).

Os critérios estabelecidos para a participação na pesquisa foram os seguintes: estar em um dos projetos voltados para a inserção das pessoas com transtorno mental no trabalho formal, que se constituiu como campo da pesquisa; ter entre 18 e 65 anos; estar em tratamento de saúde mental; encontrar-se em quadro estável (uma vez que as equipes deveriam indicar apenas pessoas em tratamento e consideradas estáveis do ponto de vista psiquiátrico e psicossocial, bem como em condições de participar da pesquisa); possuir experiência no mercado de trabalho (anterior ou atual); manifestar interesse em participar da pesquisa; e não ser considerado legalmente incapaz para a vida civil, uma vez que a manifestação de vontade foi um critério de elegibilidade fundamental. Já em relação à participação dos profissionais, o único critério estabelecido foi possuir experiência superior a seis meses na inserção de pessoas com transtorno mental no trabalho formal (VENÂNCIO et al., 1997).

O trabalho tem sido elemento presente no campo da reforma psiquiátrica desde final dos anos de 1970. Foram muitas tentativas e experiências que concebiam o trabalho como "ideal pedagógico" ou como instrumento de cuidado. Mais recentemente, ações sistemáticas voltadas para a inserção 


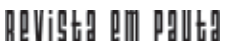

\} APONTAMENTOS SOBRE A INSERÇÃO DAS PESSOAS COM TRANSTORNO - GOMES, T. M. S. \}

DOI 10.12957/REP.2017.30383

formal no trabalho das pessoas com transtorno mental (vínculo celetista) podem ser identificadas no Rio de Janeiro a partir de 2005, com a implantação do Projeto Gerência de Trabalho (PGT). Em abril de 2012 tem-se, como desdobramento das discussões em torno da Convenção dos Direitos das Pessoas com Deficiência da ONU de 2006, o procedimento promocional no 002290.2011.01.000/3 do Ministério Público do Trabalho do Rio de Janeiro (MPT/RJ). O procedimento promocional foi resultado do grupo de trabalho que envolveu distintos atores: Estado (Núcleo de Saúde Mental e Trabalho - Nusamt), Judiciário (Organização dos Advogados do Brasil/ Ministério Público do Trabalho) e sociedade civil organizada (associações de familiares e usuários). As discussões desse grupo tiveram como principal objetivo fomentar políticas públicas de inserção das pessoas com transtorno mental no trabalho formal.

A existência do PGT foi o que consubstanciou a decisão do MPT/ $\mathrm{RJ}$, que buscou, com o expediente do procedimento promocional e do ponto de vista jurídico, viabilizar a inserção das pessoas com transtorno mental no trabalho formal. A partir do referido procedimento, o Nusamt colocou em prática suas ações de inserção no trabalho formal por meio do Projeto de Inclusão Social pelo Trabalho (Pistrab)3.

O PGT é um projeto de natureza privada que atua em parceria com uma rede de supermercados no município do Rio de Janeiro há, pelo menos, seis anos. É definido como um projeto de

inclusão social que foi desenvolvido com o objetivo de não só ampliar as ações de resgate da cidadania de pessoas com transtornos mentais (por meio do trabalho formal) bem como de oferecer às empresas a oportunidade de investir em novos conhecimentos sobre gestão de pessoas, propondo novas ações de responsabilidade social. (SALIS, 2013, p. 759).

O projeto atua como um elo fundamental articulando as demandas de trabalho formal por parte das pessoas com transtorno mental e as necessidades de contratação desse tipo de força de trabalho por uma rede de supermercados no município do Rio de Janeiro ${ }^{4}$.

Já o Pistrab surgiu das reuniões ocorridas no Núcleo de Saúde Mental e Trabalho da Secretaria de Trabalho e Renda do Rio de Janeiro (Setrab-RJ) e foi implementado em três instituições públicas no Rio de Janeiro:

\footnotetext{
${ }^{3}$ O Núcleo de Saúde Mental e Trabalho (Nusamt) é um programa coordenado pela Secretaria Estadual de Trabalho e Renda e foi integrado à Superintendência de Saúde, possuindo um formato intersetorial. Existe desde 2000 e é um programa pioneiro no país, sendo fundamentado pela Lei Estadual n. 4323/04. Seu principal objetivo é a reflexão, elaboração e implementação de políticas públicas de trabalho e geração de renda no campo da saúde mental.

${ }^{4} \mathrm{O}$ PGT não se constitui como uma empresa terceirizada para a contratação de pessoas com transtorno mental. Inversamente, ele se propõe a auxiliar na captação, seleção e manutenção daquelas pessoas para o trabalho na rede de supermercados. Assim sendo, é importante deixar claro que vínculo trabalhista dos funcionários com transtorno mental é com a empresa de supermercados, ficando o PGT como uma referência de suporte ao trabalho.
} 


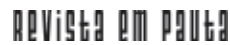

\} APONTAMENTOS SOBRE A INSERÇÃO DAS PESSOAS COM TRANSTORNO - GOMES, T. M. S. \}

DOI 10.12957/REP.2017.30383

Centro Psiquiátrico Rio de Janeiro (CPRJ), Instituto Municipal de Assistência à Saúde Juliano Moreira (Imas Juliano Moreira) e Instituto de Psiquiatria da Universidade Federal do Rio de Janeiro (Ipub). Esses polos funcionam no interior de serviços de assistência à saúde mental que já possuíam alguma atuação na inserção das pessoas com transtorno mental no trabalho.

O Pistrab é organicamente vinculado ao Núcleo de Saúde Mental e Trabalho da Secretaria de Estado de Trabalho e Renda do Rio de Janeiro (Setrab) e foi desenvolvido com objetivo de viabilizar a inserção das pessoas com transtorno mental no trabalho. Conta com a participação de profissionais, usuários, familiares e gestores da rede de saúde mental do Rio de Janeiro, que se reúnem com regularidade para problematizar e implementar ações de inserção daquele público no trabalho.

Esse projeto foi positivamente impactado pelos desdobramentos do procedimento promocional no 002290.2011.01.000/3 do Ministério Público do Trabalho do Rio de Janeiro (MPT/RJ), sob a Lei n. 8.213/1991, que dispõe sobre os benefícios da previdência social. Essa é conhecida no senso comum como "lei de cotas", porque preconiza a reserva, por parte de instituições, de percentual de vagas para inserção de pessoas com deficiência no mercado de trabalho. A Lei n. 8.213/91, no seu artigo 93, preconiza que empresas com mais de 100 funcionários devem reservar um percentual de vagas para pessoas com deficiência (entre 2 e 5\%). Em 2006 ocorreu a publicação da Convenção dos Direitos das Pessoas com Deficiência (CDPD) da ONU, da qual o Brasil é signatário. A convenção foi promulgada no país em 2009, passando a ter força de lei.

Do ponto de vista jurídico, a CDPD da ONU de 2006 pode ser considerada um marco no que diz respeito à inserção das pessoas com transtorno mental no trabalho formal no Brasil. Isso se deve por duas questões fundamentais: em primeiro lugar, a incorporação inédita dos transtornos mentais na convenção, por meio do uso do termo deficiência mental (que na convenção aparece distinto do termo deficiência intelectual). Em segundo lugar, porque indica a necessidade de ações de inclusão dessas pessoas, contemplando, dessa forma, a inserção formal no trabalho com direitos. Apesar dos avanços que promove, não é possível desconsiderar o imbróglio conceitual que causa ao aproximar dois campos com trajetórias e características distintas: transtorno mental e deficiências. A esse respeito, sugerese leitura de Sassaki (2010, 2012).

Ou seja, já que nessa convenção, pela primeira vez, incorporou-se no texto as pessoas com transtorno mental sob a denominação de pessoas com deficiência mental, instaurou-se a possibilidade jurídica de que essas pessoas pudessem ser contempladas pelo artigo 93 da Lei n. 8.213/91, em função da terminologia "deficiência", referindo-se também aos transtornos mentais.

Pode-se afirmar que a associação entre normalidade e trabalho formal não é fortuita. Pesam sobre ela as consequências da concepção específica do trabalho na sociedade capitalista, em que essa atividade se 


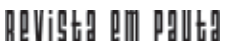

\} APONTAMENTOS SOBRE A INSERÇÃO DAS PESSOAS COM TRANSTORNO - GOMES, T. M. S. \}

DOI 10.12957/REP.2017.30383

constitui como elemento central, quer dizer, como principal categoria de mediação social (POSTONE, 2014). Dessa maneira, faz com que os sujeitos precisem da inscrição e do reconhecimento propiciados pelo trabalho para que possam ter o senso de pertencimento social.

Dada a relevância que o trabalho assume do ponto de vista ontológico (como categoria fundante do ser social) e do ponto de vista da sua centralidade na sociedade do capital, busca-se apresentar, no presente artigo, problemáticas analisadas a partir dos resultados da pesquisa: a dialética dos sentidos do trabalho presente no discurso dos entrevistados, bem como a recorrência do trabalho formal e com direitos como atividade produtiva ideal capaz de forjar pertencimento social, a despeito das condições objetivas de contratação e de sua capacidade remuneratória.

Para isso, recorre ao debate sobre a categoria trabalho de modo a indicar seus fundamentos ontológicos e seu caráter específico no capitalismo. Entende-se, pois, que nessa formação social o trabalho se constitui como principal categoria de mediação social, sendo um pressuposto fundamental para a compreensão da relevância dos debates sobre inserção formal das pessoas com transtorno mental no trabalho, considerando as várias possibilidades de inserção nessa atividade: cooperativas, oficinas e trabalho protegido ${ }^{5}$. Ademais, a maior parte dos estudos e pesquisas que investigam essa temática no campo da saúde mental não conceituam a categoria trabalho, sendo recorrente a sua utilização enquanto sinônimo de emprego.

Sabe-se que o ocultamento da dimensão estrutural do trabalho tende a reproduzir a valorização do trabalho abstrato. É necessário ao capitalismo buscar, sempre que possível, organizações pacífico-eficazes de todas as esferas da vida. Isso requer, necessariamente, a suspensão das questões ontológicas, quando se torna dispensável o conhecimento sobre o ser das coisas (LUKÁCS, 1979). A valorização exclusiva do que é eficaz e práticooperatório conduz a uma restrição apenas ao existente, ao imediatamente posto, a um tipo de comportamento, por parte dos sujeitos, mais reativo do que criativo.

A maior aproximação com o campo revelou, portanto, ser preciso que as áreas que investigam essa temática consigam problematizar conceitualmente o trabalho, identificando sua especificidade no contexto sóciohistórico capitalista contemporâneo e seus efeitos objetivos e simbólicos na vida desses sujeitos. Além disso, acredita-se que as noções abstratas ou imprecisas de cidadania e de trabalho, identificadas nos textos teóricos e políticos analisados pela pesquisa, têm pouco a contribuir na compreensão de alguns desses fenômenos.

\footnotetext{
${ }^{5}$ A despeito das atividades de inserção dessas pessoas no trabalho por meio dos projetos de geração de renda da rede nacional de saúde mental, além das cooperativas, percebemos, em pesquisas anteriores (GOMES, 2003, 2006) REFERENCIAR, que os usuários faziam uma distinção qualitativa entre o trabalho realizado nos projetos de geração de renda, identificado como mera ocupação de tempo, e o trabalho formal, identificado como atividade produtiva socialmente legitimada.
} 


\section{O trabalho como categoria de mediação social}

Em Marx, o trabalho aparece como expressão viva da contradição entre positividade e negatividade (ANTUNES, 2011). Compreendido como atividade mediadora da relação entre homem ${ }^{6}$ e natureza, composta necessariamente por duas dimensões de igual importância ontológica (teleologia e causalidade), o trabalho, elemento inalienável da existência humana, constitui-se, assim, em necessidade eterna do homem (MARX, 1971). Cabe ressaltar que essa mediação é viabilizada por intermédio da consciência. No caso dos homens, a consciência, a partir da atividade do trabalho, deixa de ser um epifenômeno, algo marginal, como ocorre com os animais.

Para Lukács (1979), a especificidade ontológica do ser social é constituída pelo reflexo ${ }^{7}$ e pelo pôr, que correspondem a modos diferentes de se considerar a realidade. Isso nos remete à separação entre sujeito e objeto, movimento mediado pela consciência.

O ser social se apresenta na dualidade heterogênea fundamental formada pelo próprio ser e por seu reflexo na consciência. Isso quer dizer que, ontologicamente, o ser social se divide entre ser e o seu reflexo na consciência, que o distingue do reino animal e pressupõe o distanciamento entre sujeito e objeto. Na natureza, a consciência está voltada tão somente à adaptação, ao patamar de reprodução biológica, e não envolve a criação do novo. Não há, portanto, dimensão de criação tal qual ocorre com a consciência humana, que é socialmente determinada. Para que o homem possa conhecer o mundo, o afastamento entre o sujeito (e a sua consciência) e o objeto (a realidade que se pretende conhecer) é uma condição. Nesse sentido, dadas as características do trabalho e para que ele se realize, essa configuração tem que estar presente. Ou seja, para ser objeto pensado, o objeto deve estar separado do sujeito no plano da consciência.

A relação entre sujeito e objeto no complexo do trabalho está posta a partir da posição teleológica, na qual a separação entre sujeito e objeto e a capacidade de reprodução na consciência do mundo objetivo são fundamentais para a posição do fim no processo de trabalho, como indica Lukács (1979, p. 15): "Se o sujeito, enquanto separado na consciência do mundo objetivo, não fosse capaz de observar e reproduzir no seu ser em si este último, jamais aquela posição do fim, que é o fundamento do trabalho, mesmo do trabalho primitivo, poderia realizar-se".

O trabalho enquanto atividade de transformação da natureza é categoria fundante do ser social. Está na base de constituição do ser social e se estabelece como condição fundante da existência social do sujeito (LUKÁCS, 1979; MARX, 1971). Em virtude dessa condição, é um dos ins-

\footnotetext{
${ }^{6}$ Cabe esclarecer que o termo "homem" não é utilizado neste artigo para fazer referência aos indivíduos do sexo masculino, mas a homens e mulheres de uma forma geral, enquanto seres humanos e sociais.

7 Em Lukács (1979), o reflexo, apesar de não ser sequer considerado como existência espectral, aparece como condição fundamental para pôr, em sentido ontológico, as séries causais.
} 


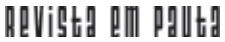

\} APONTAMENTOS SOBRE A INSERÇÃO DAS PESSOAS COM TRANSTORNO - GOMES, T. M. S. \}

DOI $10.12957 /$ REP.2017.30383

trumentos de mediação das relações entre homens e natureza. Para Marx (1971) o trabalho concreto é considerado como condição da liberdade humana e de humanização do homem e de suas relações. É, portanto, o dado ontológico primário, a atividade pela qual o homem emprega a sua energia vital com o objetivo de transformar a natureza para satisfação de sua necessidade.

Com base na perspectiva marxiana, pode-se definir o trabalho, de forma geral, como a atividade que caracteriza o homem e que possibilita o surgimento do ser social, sendo aquilo que faz exteriorizar a capacidade criadora do homem, permitindo o surgimento permanente de coisas úteis e do novo. É compreendido na sua dimensão de trabalho útil, figurando como mediação inexorável do metabolismo entre homem e natureza. Nos termos de Marx (1971, p. 184): "é a atividade vital consciente que distingue o homem imediatamente da atividade vital animal [...] só por isso ele é um ser genérico".

O trabalho é apreendido como uma atividade que possibilita a transformação constante tanto daquilo sobre o qual é empregada a energia vital do homem, quanto do próprio homem, que age no processo de trabalho. Nesse processo de permanente criação, o homem adquire novos conhecimentos e, ao mesmo tempo, cria novas necessidades. Trata-se de um movimento ininterrupto da existência humana de satisfação de necessidades através da produção de valores de uso. Sendo assim, o trabalho, cuja utilidade está representada no valor de uso de seu produto, é definido por Marx (1971, p. 149) como um trabalho útil, que pode ser compreendido também como "um processo que emancipa o homem e a natureza, processo em que o ser humano com sua própria ação impulsiona, regula e controla seu intercâmbio material com a natureza".

A importância do debate acerca do trabalho é destacada por Kosik (2011, p. 198) ao indicar que, como problemática filosófica, a busca pela compreensão sobre o que é o trabalho acompanha "todas as investigações sobre o ser do homem, desde que o problema 'quem é homem' seja concebido como problemática ontológica". O autor ainda adverte que algumas áreas, tais como a sociologia do trabalho, a fisiologia do trabalho e a teologia do trabalho, examinam determinados aspectos do trabalho, mas não tocam no problema central, que seria responder/compreender o que ele é.

É importante salientar, no entanto, que não ignoramos a proposição do autor no que tange à crítica à abordagem do trabalho a partir da oposição de pares dialéticos. Kosik (2011) propõe que a análise do trabalho considere todas as dimensões sem privilegiar um par ou outro. Afirma, ainda, que "enquanto se esgotar ou se caracterizar o trabalho mediante um único par de opostos dialéticos [...] os membros de tais pares se apresentam como categorias e a análise do trabalho se torna a análise de categorias" (KOSIK, 2011, p. 200-201). Sobre esse debate, sugere-se leitura de Kosik (2011) e de Lukács $(1978,1979)$. 


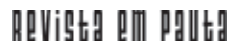

\} APONTAMENTOS SOBRE A INSERÇÃO DAS PESSOAS COM TRANSTORNO - GOMES, T. M. S. \} DOI 10.12957/REP.2017.30383

Além disso, a especificidade do trabalho situa-se, para Kosik (2011), no agir objetivo do homem, constituindo-se como um agir humano que se move na esfera da necessidade e afirma que esse é o sentido filosófico do trabalho. Sendo assim, o homem se confirma como ser genérico precisamente porque, diferente do animal, consegue construir coisas para além de suas necessidades imediatas e para além das necessidades imediatas de sua espécie.

Na perspectiva ontológica, o trabalho constitui-se como complexo fundador do ser social, mas nem por isso ele o esgota. O complexo do trabalho possui importância progressivamente declinante diante do surgimento dos outros complexos necessários à existência e ao desenvolvimento do ser social. A esse respeito, Netto e Braz (2006, p. 43) posicionam-se da seguinte forma:

Quanto mais se desenvolve o ser social, mais as suas objetividades transcendem o espaço ligado diretamente ao trabalho. No ser social desenvolvido, verificamos a existência de esferas de objetivação que se autonomizam das exigências imediatas do trabalho - a ciência, a filosofia, a arte etc. $\mathrm{O}$ trabalho, porém, não só permanece como objetivação fundante e necessária do ser social - permanece ainda como o que quase poderia chamar de modelo das objetividades do ser social.

Na perspectiva marxiana, as relações sociais que vêm caracterizar o capitalismo podem ser analisadas a partir de uma de suas propriedades, ou seja, a categoria mercadoria, cuja referência não está restrita a um produto, mas a toda dinâmica social. Para Postone (2014, p. 67),

na estrutura da teoria madura de Marx, o trabalho no capitalismo é diretamente social porque age como uma atividade de mediação social. Essa qualidade, que é historicamente única, distingue o trabalho no capitalismo do trabalho em outras sociedades e determina o caráter das relações sociais na formação capitalista [...] o caráter diretamente social do trabalho constitui uma forma de mediação social específica do capitalismo.

De acordo com Postone (2014), uma análise correta do capitalismo, baseado em Marx, deve partir do que o autor postula como caráter histórico específico do trabalho no capitalismo, cuja determinação básica Marx denomina de caráter duplo do trabalho. Esse duplo caráter do trabalho é determinado pela mercadoria e se expressa no valor e no valor de uso. Não reconhecer o caráter histórico do trabalho é assumi-lo de maneira acrítica, como trans-histórico.

Na sociedade capitalista, cujas relações caracterizadoras são determinadas pela mercadoria, o trabalho objetivo de uns é o meio através do qual se adquire bens produzidos por outros, ou seja, o trabalho, nessa sociedade, é realizado com vistas à aquisição de outros produtos. Independente 


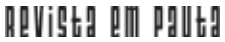

\} APONTAMENTOS SOBRE A INSERÇÃO DAS PESSOAS COM TRANSTORNO - GOMES, T. M. S. \}

DOI 10.12957/REP.2017.30383

do seu conteúdo, o produto enquanto mercadoria é ao mesmo tempo valor de uso e meio de troca (POSTONE, 2014).

O capitalismo se caracteriza pelo fato de que suas relações sociais são fundamentalmente forjadas pelo trabalho. Esse, por sua vez, objetiva-se tanto nos produtos materiais quanto nas próprias relações sociais objetivadas, ou seja, "o duplo caráter do trabalho determinado por mercadorias é tal que a esfera do trabalho no capitalismo medeia relações que, em outras formações, existem como uma esfera de interação social aberta" (POSTONE, 2014, p. 184).

Essa é uma característica das formações sociais com predominância da produção e troca de mercadorias, fazendo com o que o próprio trabalho se constitua como uma mediação social, quando "o caráter das relações sociais e o caráter social do trabalho no capitalismo passam a ser determinados por uma função social do trabalho que substitui a das relações sociais abertas" (POSTONE, 2014, p. 177). O autor explica que, numa formação social sem a predominância da forma mercadoria, a distribuição social do trabalho e do que é produzido pelo trabalho é multideterminada por outros fatores, como costumes, laços tradicionais e relações abertas de poder.

Nas sociedades pré-capitalistas, os sujeitos não se relacionavam como trabalhadores, quer dizer, o trabalho não funcionava como principal categoria mediadora social. No entanto, na sociedade capitalista, o trabalho possui centralidade, é uma categoria historicamente específica.

A generalização da relação mercantil pressupõe a dissolução de todas as formas de sociabilidade que precedem a sociedade capitalista. A circulação generalizada de mercadorias põe os sujeitos em relação como trabalhadores, reduzidos e simplificados a essa condição, fazendo com que os sujeitos tenham que trabalhar para pertencer.

Considera-se que a razão pela qual todas as dimensões da vida giram em torno do trabalho nessa organização societal seja a necessidade permanente de produção de valor; em outras palavras, de produção de mais-valor, num processo indeterminado (do ponto de vista do capital) de valorização.

Na formação social do tipo capitalista, fora das trocas, os sujeitos são meros indivíduos privados (DUAYER, 2012). Nesse aspecto, o pertencimento está garantido por meio do trabalho, que se apresenta aos sujeitos como uma conexão externa, mas que, apesar disso, assume status de mediador social privilegiado. Atestar isso não equivale a concordar com a positividade dessa forma de trabalho, dada a já consagrada propositura marxiana e marxista sobre o duplo caráter dessa categoria, mas reconhecer as principais características de sua forma específica no capitalismo.

Portanto, pode-se afirmar, com base em Lukács (1979), Postone (2014) e Duayer (2012), depois de Marx (1971), que uma das principais características da forma específica do trabalho é que ele se constitui como 


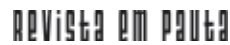

\} APONTAMENTOS SOBRE A INSERÇÃO DAS PESSOAS COM TRANSTORNO - GOMES, T. M. S. \}

DOI 10.12957/REP.2017.30383

atividade desprovida de sentido consciente (POSTONE, 2014). Em consequência, o produtor não se reconhece no produto final de seu trabalho. Dessa maneira, através do valor, o trabalho se apresenta como atividade estranhada, processo no qual a própria sociedade, enquanto produto das relações de produção e reprodução dos homens, aparece aos sujeitos como uma estrutura social autônoma.

Uma segunda característica referida à especificidade do trabalho é que, não fosse a busca pelos objetivos da sociedade capitalista, o desenvolvimento progressivo das forças produtivas possibilitaria uma demanda igualmente progressiva de menos trabalho vivo. Dito em outras palavras, o aumento da produtividade social deveria corresponder à redução de trabalho e de atividade reiterativa com consequente liberação de tempo para investimento dos sujeitos em outras áreas da vida. Se, ao contrário disso, o trabalho como valor na sociedade capitalista é o primeiro e o principal elemento da sociabilidade, quando as pessoas adquirem a condição de supérfluas para esse sistema, fora do trabalho e da possibilidade de acessá-lo, pode ocorrer um processo de perdas, de sofrimento e de rupturas sociais e afetivas.

Sabe-se que as formas de subjetividade tendem a estar em conformidade com as relações sociais e de produção hegemônicas. Na sociedade capitalista, essas subjetividades são forjadas considerando o papel de preponderância do trabalho em sua dupla relevância: como principal forma de manutenção da reprodução material da maior parte dos sujeitos e, em íntima relação com isso, por se constituir como principal meio de socialização.

Conforme sinaliza Duayer (2012), essas relações sociais às quais se faz referência são postas, ativadas e reproduzidas através das ações cotidianas pelos mesmos sujeitos portadores daquelas mesmas subjetividades que forjam essas relações, que vêm sendo menos toleradas e têm causado inúmeras formas de sofrimento.

Se, como afirma Postone (2014), o trabalho se constitui como a principal categoria de mediação social no capital, deve-se recordar que as pessoas com transtorno mental foram, desde o início dessa formação social, despojadas de seus direitos civis em nome da necessidade de tratamento, num campo médico que preconizava um nexo causal entre isolamento e reestabelecimento das condições psíquicas dos sujeitos. Dessa forma, sob as referências socioculturais da sociedade do capital, a idealização do trabalho assalariado por aqueles que nele não estiveram historicamente inseridos - e que são ainda vistos como sujeitos passivos que precisam de cuidado e supervisão - talvez não se apresente necessariamente como uma contradição.

Assim, em que pesem as consequências nocivas do trabalho assalariado para o gênero humano - constrangimentos dos próprios desejos e ne-cessidades, alienação do trabalho, do processo de trabalho e do resultado do trabalho, subsunção à mercadoria, entre outros -, não se pode ne- 


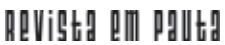

\} APONTAMENTOS SOBRE A INSERÇÃO DAS PESSOAS COM TRANSTORNO - GOMES, T. M. S. \}

DOI 10.12957/REP.2017.30383

gligenciar que o trabalho assalariado se configura em uma das principais atividades de socialização dos homens na sociedade capitalista, além de se constituir como forma de garantia da base material da vida para aqueles que não detêm os meios de produção.

Alguns estudos sobre esse tema demonstram que parte significativa das pessoas institucionalizadas nos manicômios e instituições congêneres pertencia à classe trabalhadora (ENGEL, 2001; BASAGLIA, 2005). Essa é uma indicação que se mantém extremamente atual em relação ao estudo aqui apresentado. Parte significativa das pessoas com transtorno mental em tratamento nos serviços públicos de saúde mental, para as quais o trabalho é uma questão importante, pertence à classe trabalhadora. Tendo como referência o sistema social capitalista, compreende-se que o trabalho é uma dimensão atrelada à constituição da identidade psíquica da classe trabalhadora. Contraditoriamente, a discussão sobre classe social é secundarizada no próprio campo da reforma psiquiátrica (ROSA; CAMPOS, $2013)^{8}$.

No que tange a esse argumento, é preciso considerar, ainda, que atualmente a maior parte das estratégias de inserção das pessoas com transtorno mental no trabalho informal, no município do Rio de Janeiro, ocorre nos serviços de atenção em saúde mental vinculados ao Sistema Único de Saúde (SUS). Comumente, a maioria da população atendida por esse sistema é proveniente da classe trabalhadora, a despeito de constitucionalmente o SUS se configurar como um sistema de saúde de acesso universal.

Ademais, considerando que os mecanismos ideológicos são capazes de universalizar ideias e valores que correspondem a interesses particulares de determinadas classes, a experiência de classe (THOMPSON, 2001) dessas pessoas pode vinculá-las à inserção no trabalho formal como "padrão" ou algo que é "natural". Contribui para isso a construção ideológica acerca da positividade do trabalho, além das polaridades construídas historicamente, tais quais produtivo versus improdutivo e normal versus patológico, em que a normalidade se inscreve no campo da capacidade e da produtividade, e a patologia, no campo da incapacidade e da improdutividade. A questão é que essas noções (capaz versus incapaz) se espraiam para além de campos específicos da vida, atingindo a totalidade do ser, do que ele é enquanto ser e do que é capaz de forjar, fora da estreita noção do que é ou não produtivo e válido no capitalismo.

Considera-se, ainda, que a instituição do manicômio, a partir do século XVIII, possibilitou um determinado tipo de vivência aos sujeitos. A experiência do sujeito retirado do convívio social, preso a normas e rigores

\footnotetext{
${ }^{8}$ Isso não quer dizer que existe necessariamente um corte de classe no adoecimento psíquico e que somente adoeçam as pessoas da classe trabalhadora. Não obstante, o aumento dos índices de adoecimentos psíquicos tem sido alvo de preocupações e ações internacionais nos últimos anos, aparecendo relacionado às transformações econômicas, sociais e políticas que se processaram no mundo nas últimas décadas, impactando, sobremaneira, a vida dessas pessoas.
} 
institucionais (que não deixam de refletir as normas sociais), pode fazer aumentar um desejo significativo de se inserir em algo do qual ele se considera "excluído", como, por exemplo, o acesso ao trabalho formal e com direitos.

Por outro lado, a capacidade de totalização do sistema capitalista não permite a existência de nichos fora do alcance de suas ideologias e valores, razão pela qual não existem lugares santificados, já que a possibilidade de "estar fora" dessa lógica societal não está colocada. Como afirma Mészáros (2006, p. 165), "em nosso tempo histórico os que estão fora da alienação não estão em parte alguma".

\section{Trabalho e pertencimento na sociedade capitalista para as pessoas com transtorno mental}

No âmbito da saúde mental, a tônica sobre a inserção no trabalho das pessoas com transtorno mental ganhou espaço a partir da conjuntura do pós-Segunda Guerra Mundial, especificamente com a experiência da reforma psiquiátrica italiana, da qual o Brasil é seguidor.

Um importante ponto de destaque é que a contradição presente na associação entre saúde mental e trabalho situa-se no âmbito de sua aparência, e está atrelada à forma de relação social estabelecida pela racionalidade formal abstrata da sociedade burguesa. A partir dessa racionalidade foram constituídas relações de distanciamento radical com determinados grupos sociais, dentre eles aquele constituído pelas pessoas com transtorno mental.

Nota-se que a associação socialmente estabelecida entre trabalho, produtividade e normalidade, por um lado, e ociosidade, preguiça e inutilidade, por outro, foi fundamento no processo que forjou o estigma social das pessoas com transtorno mental, caracterizado essencialmente pelas ideias de periculosidade, irracionalidade e improdutividade. Todas essas ideias estavam ligadas ao capitalismo e às sociedades cindidas em classes, ao caráter estranhado da sociedade: por não dominar completamente a sua razão, o louco é "perigoso, violento e inútil" ao processo de produção capitalista ${ }^{9}$. Assim, desenvolveu-se durante aproximadamente dois séculos uma relação social com esse grupo pautada na falta de pertença.

Nas sociedades precedentes, orientadas por uma racionalidade distinta, a relação com esses grupos se estabelecia de formas diferentes e não homogêneas (nesse particular, entende-se a homogeneidade como uma característica da modernidade em relação ao tratamento das pessoas com transtornos mentais). No que tange ao trabalho de produção de valor de

\footnotetext{
${ }^{9}$ Considera-se que a relação que se institui com a questão dos transtornos mentais no capitalismo nascente possuiu um efeito pedagógico útil e funcional às necessidades do sistema naquele momento histórico.
} 


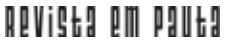

\} APONTAMENTOS SOBRE A INSERÇÃO DAS PESSOAS COM TRANSTORNO - GOMES, T. M. S. \}

DOI 10.12957/REP.2017.30383

uso, esse não era uma atividade exclusiva de pessoas consideradas "normais", impedindo que pessoas com diferentes limitações participassem da produção em ritmos diferenciados.

Historicamente, as pessoas com transtorno mental se confrontaram com atitudes baseadas na perspectiva ora da sanção, ora da tolerância. Da primeira, é decorrente a invalidação, e, da segunda, a ignorância sobre o próprio sofrimento e suas consequências na vida desses sujeitos. A sanção e a tolerância (esta última pode ser tão somente um momento no processo de transformação das relações com a loucura) suplantam a possibilidade da aprendizagem humana em suportar "o confronto com o outro que só permanece real e significativo quando o sofrimento não é isolado em lugares e ideologias que se encarreguem dele" (BASAGLIA, 2005, p. 255).

Sabe-se que, para a maioria das pessoas, as relações são marcadas por certa variedade, dependendo dos espaços frequentados. Isso não é comum no caso das pessoas com transtorno mental, especialmente aquelas que passaram pelo processo de institucionalização. Por razões variadas não é raro que, nesses casos, as pessoas tenham reduzido os seus espaços de convivência, que em situações extremas podem ficar limitados ao local de moradia e tratamento.

As principais dificuldades de inserção no mercado de trabalho das pessoas com transtornos mentais não decorrem unicamente de possíveis limitações vinculadas ao adoecimento em si, mas de fatores variados e conjugados, como as ideias e valores dominantes na sociedade, que promovem uma respectiva cultura que tende a se estabelecer como dominante. Ademais, é preciso ter claro que, além das questões de foro sociocultural envolvendo os transtornos mentais, existem sérias dificuldades de escolarização e desenvolvimento de habilidades exigidas pelo mercado de trabalho.

É importante esclarecer que este texto não se propõe à defesa acrítica da inserção das pessoas com transtorno mental na atividade alienada do trabalho formal, haja vista, entre outras razões, que o trabalho na sociedade capitalista é castrador e alienante, produtor de sofrimento. Por outro lado, conforme problematizado no item anterior, não é possível desconsiderar que todos os sujeitos estão submetidos a mecanismos repressores e ideológicos de manipulação, e que a lógica alienante do trabalho assalariado ultrapassa a condição de estar ou não diretamente inserido nessa atividade.

Basaglia (2005) alude que, na nossa sociedade, as normas coincidem diretamente com a lógica da produção. Aquele que não consegue adentrar no espaço produtivo e "positivo" do trabalho "vê-se cortado do mundo, privado de identidade e de direitos" (BASAGLIA, 2005, p. 275). Estar inserido no trabalho tem, para o referido autor, um efeito de validação da existência social do sujeito, apesar de promover, contraditoriamente, sofrimento e alienação. 


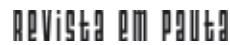

\} APONTAMENTOS SOBRE A INSERÇÃO DAS PESSOAS COM TRANSTORNO - GOMES, T. M. S. \} DOI 10.12957/REP.2017.30383

Na pesquisa realizada, a maior parte dos usuários participantes era do sexo masculino (8), tinha idade entre 30-50 anos (7), possuía um transtorno mental grave - esquizofrenia e/ou distúrbio psicótico (9) -, convivia com o transtorno mental há mais de dez anos (7), possuía escolaridade (ensino médio ou superior incompleto) e encontrava-se, no momento da pesquisa, com vínculo de trabalho formal pelas cotas $(9)^{10}$. Todos os usuários participantes estavam em tratamento no momento da participação na pesquisa.

Do total de participantes com transtorno mental, quanto à forma de chegada aos projetos de inserção no trabalho, identificou-se que oito participantes foram encaminhados por seus serviços de tratamento e quatro foram encaminhados por familiares. Dos oito participantes encaminhados pelo serviço de tratamento, apenas três indicaram terem feito o pedido do encaminhamento ao profissional de saúde, demonstrando a iniciativa em relação à inserção no emprego. Os demais relataram apenas terem concordado com a proposta apresentada pelo profissional responsável pelo acompanhamento.

No processo de pesquisa, essa questão despertou atenção por representar uma possível contradição: ao se considerar o trabalho para as pessoas com transtorno mental, acredita-se que é fundamental partir do desejo desses sujeitos de se inserirem formal ou informalmente no trabalho, considerando, inclusive, as possibilidades de agudização dos quadros de sofrimento em função da característica histórico específica do trabalho no capitalismo. Nesse particular, as falas dos usuários entrevistados demonstram que a expectativa pela inserção no trabalho por parte de familiares e, em alguns casos, profissionais era preponderante em relação ao seu próprio desejo.

Uma das questões com relação à marca deixada pelo diagnóstico de transtorno mental diz respeito ao efeito de invalidação social que este produz. Goffman (2012) demonstra que uma das formas possíveis de se buscar superar a invalidação social se dá por meio da aceitação, considerando que o sujeito "normal" pode ser definido como aquele que não se afasta das expectativas que um grupo ou a sociedade de forma geral define e projeta. O trabalho, uma das principais atividades compartilhadas pela maioria das pessoas, pode ser uma das formas encontradas para alterar essa condição.

Apesar de a maior parte dos participantes ter relatado não ter sido sua a iniciativa sobre a inserção no trabalho, a maioria apontou mudanças positivas em sua vida após o início da atividade. Sobre as consequências da inserção no trabalho, foi recorrente, na fala dos entrevistados, a noção de que ele permitiu o estabelecimento de novas relações, bem como o contato com pessoas diferentes, de modo que um dos efeitos foi a elevação da

\footnotetext{
${ }^{10}$ As "cotas" aqui mencionadas referem-se ao garantido legalmente pela Lei n. 8.213/91, em seu artigo 93, ao preconizar a reserva de vagas no trabalho em instituições com mais de 100 funcionários. Como já indicado, as pessoas com transtorno mental passam a ser contempladas por essa lei a partir da promulgação, em 2009, da Convenção dos Direitos das Pessoas com Deficiência da ONU e do entendimento do MPT/RJ em 2012.
} 


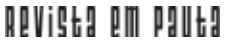

\} APONTAMENTOS SOBRE A INSERÇÃO DAS PESSOAS COM TRANSTORNO - GOMES, T. M. S. \}

DOI $10.12957 /$ REP.2017.30383

autoestima e da autonomia. Todos os participantes inseridos no trabalho indicaram esse acontecimento como um fato positivo em suas vidas.

Tais indicações expressam o valor simbólico do trabalho formal e com direitos e o seu reflexo nas relações. A compreensão dos indivíduos com transtorno mental de que a sua vida mudou com a inserção no trabalho relaciona-se também à mudança com relação à percepção que os outros tinham acerca deles. Eles não eram vistos como sujeitos sem valor e que, como tal, seriam dispensáveis. Nesse particular, a inserção no trabalho promoveu reconhecimento social.

Assim, a promoção da sociabilidade foi destacada pelas pessoas com transtorno mental como consequência fundamental proporcionada pelo trabalho. No entanto, ao lado da sociabilidade foram indicadas em todas as falas as mudanças materiais que eles puderam experimentar com a inserção no trabalho, apesar do baixo retorno remuneratório que alguns experimentavam.

Um dos projetos de inserção no trabalho formal pelas cotas mediava a contratação pela empresa com um contrato de trabalho diferenciado, cuja remuneração ocorria pelo quantitativo de horas trabalhadas no mês, como mecanismo de garantir a flexibilidade na rotina do trabalho com vistas à permanência dos sujeitos na empresa. Desse modo, alguns participantes da pesquisa recebiam abaixo de um salário mínimo.

Quanto a isso, acredita-se que, a despeito da iminente necessidade de sobrevivência material e de realização de outras demandas, independente da remuneração, o que essas pessoas podem experimentar com a inserção no trabalho diz respeito a um tipo de participação mais ativa na vida social que antes não era possível. Não se trata apenas de uma participação enquanto consumidores, possibilidade colocada independe da forma de inserção no trabalho (se formal ou informal), mas de um reconhecimento e aceitação possibilitados pela representação que a figura do trabalhador "de carteira assinada" possui em nossa sociedade, associada ao histórico estigmatizante do transtorno mental. Essa constatação é observável nas entrevistas, quando indagamos o que os usuários participantes gostariam de mudar no trabalho. Apenas três dos 12 entrevistados fizeram menção a mudar o salário.

Para essas pessoas, pelo que o material permite inferir, estar no espaço do trabalho formal, ainda que mal remunerado, é o que garante o senso de pertencimento social, reforçando os argumentos dos profissionais entrevistados. A esse respeito, reproduz-se a seguir um trecho do texto de Saraceno (1998) que é bastante elucidativo:

Hace muchos años visité un taller de rehabilitación para pacientes dentro un hospital psiquiátrico. Los pacientes producían objetos de terracota y los mandaban a unas tendas de la ciudad. La ciudad en que se encontraba el hospital era constantemente visitada por los turistas que querían comparar los objetos de terracota que son una artesanía muy renombrada de aquella ciudad. Pregunté a uno de los pacientes cómo le iba el 
negocio: vendían muchos de sus objetos de terracota? La respuesta fue simple y clara: 'ni uno vendemos [...] porque los turistas no son tontos y comparan artesanía de buena calidad en las tendas y la nuestra es fea'. Volví dos años después y me explicaron que ahora los pacientes ya no trabajan más en el hospital porque tenían una tienda propia de atesanía en la ciudad. Fui a visitarlos y con mucho entusiasmo. Otra vez hice mi pregunta: vendían mucho o poco. El mismo señor de hace dos años me contestó: 'No vendemos nada'. Y por qué? 'Los turistas miran y siguen adelante para otras tiendas que venden artesanía de mejor calidad que la nuestra'. Yo puse una cara triste pero el señor se dio cuenta e me dijo: 'Ahora sí que estamos contentos, ahora es muy diferente que antes'. Yo no veo mucha diferencia. El señor me dijo con voz clara y alegre: 'Mire, hace dos años yo era un psicótico que hacia terracota fea. Ahora yo soy el dueño de una tienda de artesanía de esta ciudad, psicótico todavía, y el business (así dijo) anda muy mal, como muchos otros en este país. Somos comerciantes en dificultades'. (SARACENO, 1998, p. 14-15).

Diante do exposto, acredita-se ter encontrado alguns elementos importantes para compreender a demanda das pessoas com transtorno mental pelo emprego, bem como a diferença que se estabelece entre esse tipo de inserção e aquela proporcionada pelas atividades de trabalho protegido (circunscritos aos serviços de saúde mental). Tendo o trabalho o seu sentido encerrado no emprego e considerando a formação socioeconômica da sociedade brasileira, apesar da histórica presença do trabalho informal, qualquer atividade livre de vínculo e de direitos torna-se menos valorizada e, muitas vezes, é associada ao não trabalho.

Percebe-se que é somente nessa sociedade, armada pelo trabalho, que os sujeitos se relacionam quase exclusivamente como trabalhadores (DUAYER, 2012). Em outras formações sociais, cujas relações não foram desenvolvidas com base no valor de troca, as pessoas não se relacionavam eminentemente como trabalhadores. Nessas sociedades, a articulação e o pertencimento dos sujeitos não se dão pelo trabalho (DUAYER, 2012) e o trabalho não se constitui, tal qual ocorre na sociedade capitalista, como principal categoria de mediação social (POSTONE, 2014). Na sociedade capitalista, o trabalho é a atividade que garante o pertencimento, enquanto que nas outras formações sociais é por pertencer que o sujeito trabalha.

Dessa forma, a análise das falas permitiu identificar que, nesse universo de pesquisa, o valor do trabalho formal e com direitos se relaciona mais ao senso de pertencimento e reconhecimento social do que ao retorno material que ele proporciona.

Ao considerar o contexto das entrevistas, foi possível perceber uma distinção importante no discurso dos usuários entrevistados. No caso daqueles que não estavam inseridos no trabalho, o discurso apresentava-se de maneira negativa, centrado na impossibilidade como consequência imutável atrelada ao adoecimento. Aqueles que estavam empregados, no entanto, expressavam-se de um lugar distinto e através de um discurso positivo. 


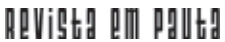

\} APONTAMENTOS SOBRE A INSERÇÃO DAS PESSOAS COM TRANSTORNO - GOMES, T. M. S. \}

DOI 10.12957/REP.2017.30383

Relatavam seus problemas e dificuldades, mas não o faziam a partir do lugar do desqualificado e da invalidação social, comumente relacionado à figura da pessoa com transtorno mental. Por mais que essa constatação, fora de um contexto teórico crítico ao trabalho, possa parecer uma apologia ao trabalho abstrato, alienado, o que percebemos foi que a inserção no trabalho formal, no emprego, possibilitou a vivência a partir de uma identidade validada e compartilhada socialmente: a de trabalhador.

Sabe-se que o trabalho, ao ser transformado em instituição, e considerando o seu significado para o conjunto das relações sociais, compreende-se que ele "instala psiquicamente um elemento organizador e estruturante do sujeito em relação ao mundo" (FERNANDES, 1990, p. 41).

Na perspectiva da desinstitucionalização, a inserção das pessoas com transtorno mental no trabalho formal não deve se colocar como uma via de normalização (embora não esteja isenta desse risco). Ao contrário, deve buscar garantir direitos gerais e específicos, tais como: flexibilidade na carga horária, garantia de continuidade no tratamento médico e terapêutico etc. Para o campo da saúde mental, em primeiro lugar, trata-se de garantir o acesso a um direito social negado historicamente a esse público, qual seja, o trabalho, para em seguida elaborar reivindicações mais específicas para esse conjunto de trabalhadores, sem abandonar as questões gerais.

O que o material analisado para a pesquisa da tese permitiu inferir é que a inserção na condição de trabalhador com carteira assinada possibilitou a vivência de uma experiência comum à maioria das pessoas nessa sociedade. Essa vivência não está isenta de outros problemas e questões, as quais as pessoas com transtorno mental não vivenciavam. A inserção no emprego, sem que se desconsidere o seu potencial negativo, demonstrou ter uma importante repercussão simbólica com potencial de efeitos políticos. Agora, compartilhando o mesmo tipo de experiência que os demais sujeitos, os indivíduos com transtornos mentais podem também se unir nas reivindicações por direitos que não sejam exclusivamente relacionados a questões de saúde mental, na luta por melhorias de condições de vida e por outra condição de trabalho (não alienado).

Do ponto de vista social, o saldo com essa inserção está situado no âmbito qualitativo das relações sociais, cuja compreensão se estabelece melhor na medida em que se torna histórico o objeto em questão, contextualizando a trajetória histórica da loucura, especialmente a partir do final século XVII.

\section{Conclusão}

A partir dos dados analisados pela pesquisa, identificou-se que a entrada no trabalho formal e com direitos, a despeito das críticas sobre ele, 


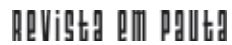

\} APONTAMENTOS SOBRE A INSERÇÃO DAS PESSOAS COM TRANSTORNO - GOMES, T. M. S. \}

DOI 10.12957/REP.2017.30383

pode representar um patamar de reconhecimento social positivo sobrepujando as associações de valores negativos atrelados à questão do transtorno mental. Em relação aos aspectos positivos, o trabalho formal propicia, de forma objetiva e simbólica, a aquisição do estatuto de cidadania, cuja importância foi forjada e reproduzida por esse sistema social. Para esses sujeitos, o trabalho proporciona pertencimento e os retira do lugar de cidadãos de segunda classe.

Se, por um lado, a forma socialmente determinada do trabalho aliena e expropria, condiciona e submete, por outro, mesmo os estudos mais comprometidos com a crítica da sociedade capitalista e, por conseguinte, do trabalho no interior dessa formação social, não podem desprezar os elementos da vida real dos sujeitos no mundo real, onde o trabalho abstrato tornou-se uma mediação central (POSTONE, 2014).

Dessa forma, acredita-se que a crítica negativa ao trabalho no capitalismo, exposta por Marx e desenvolvida por outros marxistas, é pressuposto indispensável para que se construam, por meio da práxis transformadora indicada por Mészáros (2003), estratégias e formas de superação dessa atividade alienada que o trabalho assume. No entanto, ainda segundo Mészáros (2003), isso não ocorre independente de uma tomada de consciência de seus interesses por parte da classe trabalhadora. Eis aqui o que parece ser um dos maiores desafios de nosso tempo a movimentar estudos e investigações: a necessidade histórica desse processo fundamental de tomada de consciência diante do enorme contingente populacional em escala global que se encontra desprovido da única possibilidade de sobrevivência: a venda de sua força de trabalho.

Somos forçados a começar constatando que o primeiro pressuposto de toda existência humana e, portanto de toda a história, é de que os homens devem estar em condições de viver para poder 'fazer a história'. Mas, para viver, é preciso antes de tudo comer, beber, ter habitação, vestir-se e algumas coisas mais. O primeiro ato histórico é, portanto, a produção dos meios que permitam a satisfação destas necessidades, a produção da própria vida material, e de fato este é um ato histórico, uma condição fundamental de toda história. (MARX; ENGELS, 2007, p. 39).

No universo particular em que essa temática se insere e que conduz ao debate sobre validação-invalidação social, identificou-se pela análise do material que uma das funções da inserção no trabalho é a sua capacidade de promover reconhecimento e pertencimento social, ou seja, a capacidade de "habilitar" no âmbito das relações sociais capitalistas.

O sistema sociometabólico (MÉSZÁROS, 2003) do capital subverteu a experiência da loucura e a enquadrou no interior de um sistema científico que fosse capaz de explicá-la, normatizá-la, contê-la e adaptá-la a partir dos valores que sustentam a racionalidade hegemônica. Nesse processo, a experiência da loucura foi classificada primeiramente como 


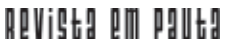

\} APONTAMENTOS SOBRE A INSERÇÃO DAS PESSOAS COM TRANSTORNO - GOMES, T. M. S. \}

DOI $10.12957 /$ REP.2017.30383

alienação mental, doença mental e finalmente como transtorno mental. No que diz respeito às três últimas denominações, muda-se a nomenclatura com o intuito de acompanhar os avanços sociopolíticos de cada tempo histórico. Contudo, em última instância, a experiência da loucura continua a significar algo que precisa ser enquadrado, ou seja, algo que está fora do padrão.

Nos marcos da sociedade capitalista, o trabalho não pode ser vivenciado como ato de liberdade. Inversamente, ele é realizado, para além da necessidade material, como necessidade de pertencimento que, no atual estágio do desenvolvimento social, pode ser concebido pela limitada condição de exercício da cidadania. Portanto, antes de o trabalho ser um ato de liberdade, ele é atividade que garante esse pertencimento.

No capitalismo, a liberdade quase que desaparece em função da coerção para a produção de valor. Nesse processo, em que o trabalho voltase para a produção de valor - produzir dinheiro em forma de coisa -, a coerção se dá de forma ainda mais violenta, porque muitas vezes é irreconhecível. Desse modo, forja, por meio da violência econômica e simbólica, a subordinação dos trabalhadores às constrições impostas por esse trabalho, do qual, ao que parece, ainda não se pode escapar isento dos riscos sociais e simbólicos que o lugar do não trabalho impõe ao sujeito.

Reitera-se, portanto, a assertiva de Castel (1998) e Antunes (2005) acerca da importância do trabalho para além da sua dimensão estritamente econômica, quer dizer, para a sua relevância no universo simbólico, psicológico e cultural dos sujeitos.

Nesse sentido, sem perder de vista o horizonte particular da trajetória da loucura na sociedade capitalista, aventa-se que a percepção do trabalho como atividade comum a todos os sujeitos desta formação social (portanto, de quem é "normal") não é exclusiva das pessoas com transtorno mental. O que há de particular em relação ao grupo em questão foi a sua não representatividade histórica nesse universo do trabalho historicamente específico, justificada pelo suposto conteúdo negativo inerente ao transtorno mental. 


\section{Referências}

ANTUNES, R. O continente do labor. São Paulo: Boitempo, 2011.

. R. O Caracol e sua concha: ensaio sobre a nova morfologia do trabalho. São Paulo: Boitempo, 2005.

BASAGLIA, F. Escritos selecionados em saúde mental e reforma psiquiátrica. Rio de Janeiro: Garamond, 2005.

BRASIL. Lei n. 8.213 de 24 de julho de 1991. Dispõe sobre os planos de benefícios da previdência social e dá outras providências.

CASTEL, R. As metamorfoses da questão social: uma crônica do salário. Petrópolis: Vozes, 1998.

DUAYER, M. Marx e a crítica ontológica da sociedade capitalista. Revista Em Pauta, Rio de Janeiro, v. 10, 2012.

ENGEL, M. Os delírios da razão: médicos, loucos e hospícios. Rio de Janeiro: Editora Fiocruz, 2001.

FACCHINETTI, C. Philippe Pinel e os primórdios da medicina mental. Revista Latinoamericana de Psicopatologia, São Paulo, v. 11, n. 3, set. 2008.

FERNANDES, M. I. A. A subjetividade à luz de uma teoria de grupos. Psicologia USP, São Paulo, v. 1, n. 1, 1990.

GOFFMAN, E. Estigma: notas sobre manipulação da identidade deteriorada. Rio de Janeiro: LTC, 2012.

GOMES, T. M. da S. Para além da rima pobre do capital: questões sobre a inserção de pessoas com transtorno mental no trabalho formal. Tese (Doutorado) - Pontifícia Universidade Católica do Rio de Janeiro, Departamento de Serviço Social, 2014.

. T. M. da S. De cidadão e louco. O debate sobre a cidadania do louco a partir do caso do Centro de Atenção Psicossocial. Dissertação (Mestrado). UFF, Rio de Janeiro, 2006.

. T. M. da S. A serpente se foi e agora? Saúde Mental e trabalho, um caminho possível. Trabalho de Conclusão de Curso. UFF, Niterói, 2003. LUKÁCS, G. As bases ontológicas do pensamento e da atividade do homem. São Paulo: Lech, 1978.

. Para uma ontologia do ser social. 1979. Mimeo.

KOSIK, K. A dialética do concreto. São Paulo: Paz e Terra, 2011.

MÂNGIA, E. F. Psiquiatria e tratamento moral. Revista de Terapia Ocupacional, São Paulo, v. 8, n. 2/3, 1997.

MARX, K. O capital. Vol. 1. Rio de Janeiro: Civilização Brasileira, 1971. 
MARX, K.; ENGELS, F. A ideologia alemã. São Paulo: Boitempo, 2007. MÉSZÁROS, I. Para além do capital: rumo a uma teoria da transição. Campinas: Editora Unicamp, 2003. . A teoria da alienação em Marx. São Paulo: Boitempo, 2006.

NETTO, J. P.; BRAZ, M. Economia política: uma introdução crítica. São Paulo: Cortez, 2006.

NICÁCIO, F. N.; MANGIA, E. F.; GHIRARDI, M. I. G. Projetos de inclusão no trabalho e emancipação de pessoas em situação de desvantagem: uma discussão de perspectivas. Revista de Terapia Ocupacional, São Paulo, v. 16, n. 2, maio/ago. 2005.

POSTONE, M. Tempo, trabalho e dominação social. Rio de Janeiro: Boitempo Editora, 2014.

ROSA, L.; CAMPOS, R. Saúde mental e classe social: Caps, um serviço de classe e interclasse. Revista serviço social e sociedade, São Paulo: Cortez, n. 144, abr./jun. 2013.

ROTELLI, F.; DE LEONARDIS, O.; MAURI, D. Desinstitucionalização. São Paulo: Ed. Hucitec, 2001.

SALIS, A. C. Projeto gerência de trabalho e inclusão social de usuários de saúde mental. Revista Psicologia: ciência e profissão, v. 33, n. 3, 2013.

SARACENO, B. La ciudadanía como forma de tolerancia. 1998. Mimeo.

SASSAKI, R. Inclusão: construindo uma sociedade para todos. Rio de Janeiro: WVA, 2010.

. Causa, impedimento, deficiência e incapacidade, segundo a inclusão. Revista Reação, São Paulo, ano XIV, n. 87, jul./ago. 2012.

THOMPSON, E. P. As peculiaridades dos ingleses e outros artigos. São Paulo: Editora da Unicamp, 2001.

VENÂNCIO, A. T. et al. O campo da atenção psicossocial. Rio de Janeiro: Te Corá Editora, 1997.

Recebido em 01 de maio de 2016.

Aprovado para publicação em 11 de agosto de 2016.

DOI 10.12957/rep.2017.30383

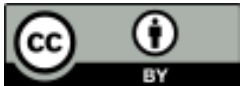

A Revista Em Pauta: Teoria Social e Realidade Contemporânea está licenciada com uma Licença Creative Commons Atribuição 4.0 Internacional. 